\title{
Use of modified resistogram to type Candida albicans isolated from cases of vaginitis and from faeces in the same geographical area
}

\author{
P R HUNTER, CHERRY FRASER \\ From the Division of Hospital Infection, Central Public Health Laboratory, London
}

SUMMARY Ninety strains of Candida albicans were isolated from vaginal swabs taken by general practitioners from cases of vaginal candidosis. One hundred and nine strains were also isolated from 300 specimens of faeces received from outpatients living in the same geographical area. These strains were typed using a modification of the resistotyping method. We were unable to find any significant differences between the two populations of strains. This suggests that no particular resistotype has an increased ability to cause vaginitis.

Vaginitis due to Candida albicans is a common cause of visits to the general practitioner. Little, however, is known of its epidemiology. The importance of an intestinal reservoir for $C$ albicans in the pathogenesis of vaginal candidosis is well established. ${ }^{12}$ Further advances have followed the development of typing schemes for $C$ albicans. The isolation of identical resistotypes from the intestinal and genital tracts of patients with candidal vaginitis has supported the view that vaginal infection follows on from intestinal colonisation. $^{3}$ The question as to whether all strains of $C$ albicans are equally likely to colonise and then infect the vagina is unclear.

This study was undertaken to determine whether strains of $C$ albicans colonising the gut of the general population were equally likely to cause vaginitis. To answer this we compared strains isolated from cases of candidal vaginitis in the community with strains isolated from faecal samples submitted by general practitioners and environmental health officers in the same area.

\section{Material and methods}

From June to September 1986300 specimens of faeces submitted to the Cardiff Public Health Laboratory were cultured for $C$ albicans. Only faeces which had been submitted by general practitioners or environmental health officers within the Cardiff area were examined. Specimens which were frankly diarrhoeal were excluded from the study. Most of the specimens had been submitted during contact tracing or in the follow up of previously diagnosed cases of enteric infection. During this period all strains of $C$ albicans isolated from vaginal swabs, submitted by Cardiff general practitioners for the investigation of vaginal discharge, were also saved.

Culture of both faeces and vaginal swabs was on Pagano Levin agar with added triphenyltetrazolium chloride (Difco laboratories) for 48 hours at $37^{\circ} \mathrm{C}$. Characteristic colonies of $C$ albicans were confirmed by the production of germ tubes in serum after four hours of incubation at $37^{\circ} \mathrm{C}$. Strains were then subcultured on to Sabouraud slopes for transfer to the Candida reference unit for typing.

The resistotyping scheme used was Medcraft's ${ }^{4}$ modification of McCreight and Warnock's ${ }^{5}$ method. This depends on the ability of strains to grow on agar plates containing various dilutions of toxic chemicals. Table 1 shows the chemicals used, their code, and concentrations. The typing set used varies from that of McCreight and Warnock ${ }^{5}$ in that silver nitrate is not included (E), but malachite green (F) and copper sulphate $(\mathrm{G})$ are. A strain was deemed to be resistant to a chemical when growth was seen on three of the four plates used for each chemical.

\section{Results}

One hundred and nine strains of $C$ albicans were isolated from 300 faecal specimens $(36 \%)$. Ninety strains 
Table 1 Chemicals used for resistotyping strains of $C$ albicans

\begin{tabular}{|c|c|c|c|c|c|c|}
\hline \multirow{2}{*}{$\begin{array}{l}\text { Chemical compound } \\
\text { Sodium selenite } \\
\text { Boric acid } \\
\text { Centrimide } \\
\text { Sodium periodate } \\
\text { Malachite green } \\
\text { Copper sulphate }\end{array}$} & \multirow{2}{*}{$\begin{array}{l}\text { Letter code } \\
\text { A } \\
\text { B } \\
\text { C } \\
\text { D } \\
\text { F } \\
\text { G }\end{array}$} & \multirow{2}{*}{$\begin{array}{l}\text { Concentration of stock } \\
\text { solution }(g / l)\end{array}$} & \multicolumn{4}{|c|}{$\begin{array}{l}\text { Volume added to resistogram plates } \\
(\mathrm{ml} / 20 \mathrm{ml} \text { agar })\end{array}$} \\
\hline & & & $\begin{array}{l}0.5 \\
1.2 \\
0.05 \\
0.3 \\
0.2 \\
1.0\end{array}$ & $\begin{array}{l}0.6 \\
1.3 \\
0.1 \\
0.4 \\
0.3 \\
1.2\end{array}$ & $\begin{array}{l}0.7 \\
1.4 \\
0.15 \\
0.5 \\
0.4 \\
1.4\end{array}$ & $\begin{array}{l}0.8 \\
1.5 \\
0.2 \\
0.6 \\
0.5 \\
1.6\end{array}$ \\
\hline
\end{tabular}

were isolated from vaginal swabs during the same period. Table 2 shows the number of strains isolated from faecal and vaginal specimens for the more commonly found resistotypes. No significant difference was found between the incidence of isolation of any resistotype from either site ( $\chi^{2}$ test). Neither were there any significant differences in the resistance of strains to any of the individual chemicals between the two sites (table 3).

\section{Discussion}

The addition of the two new chemicals to the typing set has increased the discrimination of the method. These divide what would have been the largest resistotype A-C-. (33.7\% of all strains) into three resistotypes; A-C-.F (19.6\%), A-C-.-- (8.0\%), and A-C-.FG (6.0\%). Silver nitrate has not been included in this set as we have found it to give both poor discrimination and reproducibility.

In a study of patients attending a genitourinary clinic no significant difference was found between the biotypes isolated from the vaginas of women with and without candidosis. ${ }^{6}$ Sexual transmission of $C$ albicans is known to occur, ${ }^{7}$ and may be a source of infection in women attending genitourinary clinics. Thus results from a genitourinary clinic may therefore not be applicable to the general population.

It has been suggested that women who suspect a venereal cause for their symptoms tend to attend the more anonymous genitourinary clinic, rather than

Table 2 No of strains found of particular resistotypes in faecal and vaginal isolates of Candida albicans (\%)

\begin{tabular}{lcc}
\hline Resistotype & Faecal strains & Vaginal strains \\
\hline A-C-.F- & $21(19 \cdot 2)$ & $18(20 \cdot 0)$ \\
ABC-.F- & $12(11 \cdot 0)$ & $12(13 \cdot 3)$ \\
A--.F- & $9(8 \cdot 3)$ & $8(8 \cdot 9)$ \\
A-C-.-- & $10(9 \cdot 2)$ & $6(6 \cdot 7)$ \\
A-C-.FG & $7(6 \cdot 4)$ & $5(5 \cdot 6)$ \\
AB--.F- & $4(3 \cdot 7)$ & $6(6 \cdot 7)$ \\
A--.- & $3(2 \cdot 8)$ & $6(6 \cdot 7)$ \\
A--.FG & $5(4 \cdot 6)$ & $4(4 \cdot 4)$ \\
-BC-.F- & $5(4 \cdot 6)$ & $1(1 \cdot 1)$ \\
ABC-.FG & $5(4 \cdot 6)$ & $1(1 \cdot 1)$ \\
Ot.-- & $3(2 \cdot 8)$ & $3(3 \cdot 3)$ \\
Tthers & $25(22 \cdot 9)$ & $20(22 \cdot 2)$ \\
Total & $109(100)$ & $90(100)$ \\
\hline
\end{tabular}

their general practitioners. ${ }^{8}$ If this is true then sexual transmission of $C$ albicans was less common in our study than in the study of patients attending a genitourinary clinic. ${ }^{6}$ In most of our study group, therefore, infection is likely to have been endogenous and due to organisms already colonising the intestinal tract. That no significant differences were found between resistotypes causing vaginitis and those colonising the intestinal tract in the community as a whole, suggests that no particular resistotype is more virulent than any other. All resistotypes found colonising the human intestine seem equally likely to colonise and then infect the human vagina.

An important virulence factor for $C$ albicans in superficial candidal infections is thought to be adherence to epithelial cells. ${ }^{910}$ This adherence varies between strains. ${ }^{11} 12$ These studies found some corô relation between cellular adherence, pathogenicity fo mice, and phospholipase activity ${ }^{12}$ or proteinase activity. ${ }^{11}$ One study ${ }^{11}$ suggested that strain type ${ }^{+}$ --C--. which was the most common isolate, was also the most pathogenic. This resistotype was found only rarely in our study.

In other micro-organisms the association of known types with increased virulence has been shown. This is particularly so for Escherichia coli ${ }^{13}$ and also for Haemophilus influenzae type b. ${ }^{14}$ These associations, however, are usually with antigens on the cell surface which have an important role in the pathogenesis of infection. The association between types designated by other typing schemes and virulence does occur but is less well defined.

Both this work and that of the study of genitourinary patients ${ }^{6}$ have failed to associate any particular type of $C$ albicans with vaginal candidosis. This may mean that all strains of $C$ albicans are

Table 3 No of strains resistant to individual agents used (\%)

\begin{tabular}{lll}
\hline Code & Faecal strains & Vaginal strains \\
\hline A & $96(88 \cdot 0)$ & $74(82 \cdot 2)$ \\
B & $41(37 \cdot 6)$ & $28(31 \cdot 1)$ \\
C & $76(69 \cdot 7)$ & $53(58 \cdot 9)$ \\
D & 0 & 0 \\
F & $77(70 \cdot 6)$ & $63(70 \cdot 0)$ \\
G & $30(27 \cdot 5)$ & $22(24 \cdot 4)$ \\
\hline
\end{tabular}


equally virulent for the vagina and that host factors are entirely responsible for the development of candidosis. It is also possible, however, that any particularly virulent strains are only randomly associated with the various known types. No information was available as to whether any of the infections were chronic or recurrent. These cases may yet be found to be due to particularly virulent strains.

We thank the staff of Cardiff Public Health Laboratory for collecting the strains and Professor EM Cooke for her help in preparing this manuscript.

\section{References}

1 Miles MR, Olsen L, Rogers A. Recurrent vaginal candidiasis. Importance of an intestinal reservoir. JAMA 1977;238:1836-7.

2 Hilton AL, Warnock DW. Vaginal candidiasis and the role of the digestive tract as source of infection. Br J Obstet Gynaecol 1975;82:922-6.

3 Warnock DW, Speller DCE, Milne JD, Hilton AL, Kershaw PI. Epidemiological investigation of patients with vulvovaginal candidosis. British Journal of Venereal Diseases 1979;55:357-61.

4 Medcraft J. Typing of Candida and the epidemiology of candidosis. Reading: University of Reading, 1985. (Thesis.) 119-27.

5 McCreight MC, Warnock DW. Enhanced differentiation of isolates of Candida albicans using a modified resistogram method. Mykosen 1982;25:589-98.

6 Odds FC, Abbott AB, Reed TAG, Willmott FE. Candida albicans strain types from patients with and without Candida infection. Eur J Obstet Gynaecol Reprod Biol 1983;15:37-43.

7 Thin RN, Leighton M, Dixon MJ. How often is genital yeast infection sexually transmitted? Br Med J 1977;ii:93-4.

8 O'Dowd TC, Ribeiro CD, Munro J, West RR, Howells CHL, Harvard Davis R. Urethral syndrome: a self limiting illness. $\mathrm{Br}$ Med J 1984;288:1349-52.

9 Sobel JD, Myers PG, Kaye D, Levison ME. Adherence of Candida albicans to human and buccal epithelial cells. J Infect Dis 1981;143:76_R?

10 Ryley JF. Pathogenicity of Candida albicans with particular reference to the vagina. Journal of Medical and Veterinary Mycology 1986;24:5-22.

11 Ghannoum M, Abu Elteen K. Correlative relationship between proteinase production, adherence and pathogenicity of various strains of Candida albicans. Journal of Medical and Veterinary Mycology 1986;24:407-13.

12 Barrett-Bee K, Hayes Y, Wilson RG, Ryley JF. A comparison of phospholipase activity, cellular adherence and pathogenicity of yeasts. J Gen Microbiol 1985;131:1217-21.

13 Jann K, Jann B. Cell surface components and virulence. Escherichia coli $\mathrm{O}$ and $\mathrm{K}$ antigens in relation to virulence and pathogenicity. In: Sussman M, ed. The virulence of Escherichia coli. London: Academic Press, 1985:157-76.

14 Turk DC. Clinical importance of Haemophilus influenzae-1981. In: Sell SH, Wright PF, eds. Haemophilus influenzae. Epidemiology, immunology, and prevention of disease. New York: Elsevier Biomedical, 1982:3-9.

Requests for reprints to: Dr PR Hunter, Division of Hospital Infection, Central Public Health Laboratory, 61 Colindale Avenue, London NW9 5HT, England. 